\title{
A numerical Study on Processes of Charge and Discharge of Latent Heat Energy Storage System Using RT27 Paraffin Wax for Exhaust Waste Heat Recovery in a SI Engine
}

\author{
Habib Gürbüz ${ }^{1 *}$, Durukan Ateş² \\ 0000-0001-7069-8633', 0000-0002-6604-7384² \\ ${ }^{1}$ Department of Automotive Engineering, Faculty of Engineering, Süleyman Demirel University, 32200, Isparta/Turkey \\ ${ }^{2}$ Graduate School of Natural and Applied Sciences, Süleyman Demirel University, 32200, Isparta/Turkey
}

\begin{abstract}
In the present paper, the numerical analyses of the heat charge and discharge processes of the latent heat energy storage (LHTES) system designed for the recovery of the exhaust waste heat energy of the SI engine presented. In the LHTES system as phase change material (PCM), the charge and discharge ability of paraffin wax commercially identified with code RT27 were analyzed depending on time. Two closed-loop fluid circulation system consisting of two heat exchangers (HESs) was designed, someone connected to the exhaust path of SI engine for waste heat recovery, and the other used for the charging and discharging of waste heat energy in the PCM. To transfer the waste heat from the hot exhaust gases to the PC, cold water was used as the heat carrier fluid. In the numerical analysis, the exhaust gas temperature and flow rate values of a singlecylinder, air-cooled having a stroke volume of $476.5 \mathrm{~cm}^{3}$ SI engine operated with gasoline at $1600 \mathrm{rpm}$ engine speed and 1/2 throttle position were used. As a result, at designed LHTES system and numerical analysis performed for RT27 paraffin wax under boundary conditions, the process of heat charge (melting) completed at $8000 . \mathrm{sec}$ with $93 \%$ liquid-fraction, while the process of heat discharge (solidification) completed at 55000.sec with $15 \%$ liquid-fraction.
\end{abstract}

Keywords: Latent heat energy storage, Serpentine tube heat exchanger, Exhaust waste heat recovery, SI engine.

\section{* Corresponding author \\ Habib GÜRBÜZ \\ habibgurbuz@sdu.edu.tr}

Address: Automotive Engineering Department, Faculty of Engineering, Süleyman Demirel University, 32200 Isparta, Turkey

Tel: +902462111867

Fax: +902462111072

Research Article

Manuscript

Received 27.09.2020

Revised $\quad 06.11 .2020$

Accepted $\quad 09.11 .2020$

Doi: 10.30939/ijastech..800856

\section{Introduction}

Even in today's engine technologies, approximately 30$40 \%$ of the fuel energy in vehicles with internal combustion engines (ICEs) is thrown into the atmosphere as waste heat energy [1-3]. On the other hand, carbon dioxide $\left(\mathrm{CO}_{2}\right)$ emitted into the atmosphere by the exhaust gases of internal combustion engines is the main source of greenhouse gas emissions. Also, unburned hydrocarbons (UHC), carbon monoxide (CO), nitrogen oxides $\left(\mathrm{NO}_{\mathrm{x}}\right)$ and particulate matter (PM) emissions emitted into the atmosphere from internal combustion engines pose health exposures [4-6]. The engine efficiency could be increased by approximately $4-5 \%$ by converting the exhaust waste heat energy of ICEs into useful energy with appropriate waste heat recovery systems. With a suitable heat HEX design, a considerable part of the exhaust waste heat energy could be recovered without increasing the back pressure of exhaust gas too much $[7,8]$. Recently, the latent heat thermal energy storage (LHTES) systems using PCMs as storage media for exhaust waste heat recovery are widely used by many researchers [9-10] due to its large energy storage capacity [11] and almost constant operating temperature [12] in a narrow temperature interval [13]. A wide variety of PCMs with various melting temperatures, such as paraffin waxes, organic and inorganic compounds, and hydrated salts, are used in LHTES systems [14]. LHTES systems utilize the melting/solidification enthalpy of PCMs [15]. PCMs, provide an opportunity to stabilize the thermal behaviour of the LHTES system by providing increased thermal inertia in the melting range [16]. Phase change temperature, stability, amount of latent heat, and thermal conductivity should be considered in the selection of the appropriate PCM for the system to be used [15]. Also, the melting temperature of the PCM used for exhaust heat recovery is a decisive factor in PCM selection. Generally, PCMs with a melting temperature above $293 \mathrm{~K}$ is used to storing heat [17]. On the other hand, the low thermal conductivity of most PCMs limits the performance of LHTES systems, leading to a much longer charging or 
discharging process [18]. Another disadvantage of the solid-liquid phase change process is the mechanical stability of the PCM and the volume change that occurs during the melting process [19]. Therefore, plenty of research has been done on the thermal performance of LHTES systems with different designs, operating conditions and PCMs. Sharifi et al. [20] investigated experimentally and computationally the melting and solidification of PCM surrounding a vertical heat pipe (HP), finned with metal foils in a vertical cylinder to increase the heat transfer surface area. The increase of phase change was found by increasing the heat transfer surface area of the combination of HP-metal foils. Pandiyarajan et al. [21] found that in a thermal energy storage system using a finned tube HEX and cylindrical PCM capsules, approximately $10-15 \%$ of the fuel energy can be stored as heat energy at different engine loads. Hatami et al. [22] optimized the finned-tube HEX to improve exhaust waste heat recovery in a diesel engine. It was determined that the fin height is effective on the pressure drop, and the number of fins is effective in increasing the heat recovery performance. Tiari et al. [18] simulated the heat charging process of the finned heat pipe supported LHTES system using a temporary twodimensional model. It was found that decreasing the heat pipe spacing caused the melting rate to increase and the base wall temperature to decrease. Also, natural convection accelerated the melting process and shortened the total charging time by approximately $30 \%$. Although there are PCM container arrangements in rectangular, cylindrical, spherical and annular configurations [23,24], it is common to using cylindrical PCM container structure that can be mounted both vertically and horizontally $[12,25]$. In the literature studies, it is seen that some of the exhaust waste heat energy can be converted into useful energy by using PCMs as a storage area in LHTES systems. However, additional experimentally and computationally studies are required on the appropriate PCM selection, HEX design, operating conditions and general structure of the LHTES system in terms of optimization of parameters such as charge/discharge time, phase change capability and thermal conductivity. In this paper, an LHTES system using PCM as a storage area was designed to store and reuse the exhaust waste heat energy of the SI engine. Paraffin wax commercially identified with the code RT27 was used as the PCM. Time-dependent Computational Fluid Dynamics (CFD) analyses were performed for processes of heat charge (melting) and discharge (solidification) in the LHTES system. Timedependent data and contour images of heat flux, mean temperature, liquid-fraction were obtained and interpreted.

\section{Material and Method}

In the present paper, an LHTES system for reuse by storing in PCM of the exhaust waste heat energy of the SI engine was designed. Modelling of LHTES system is given in Fig. 1.

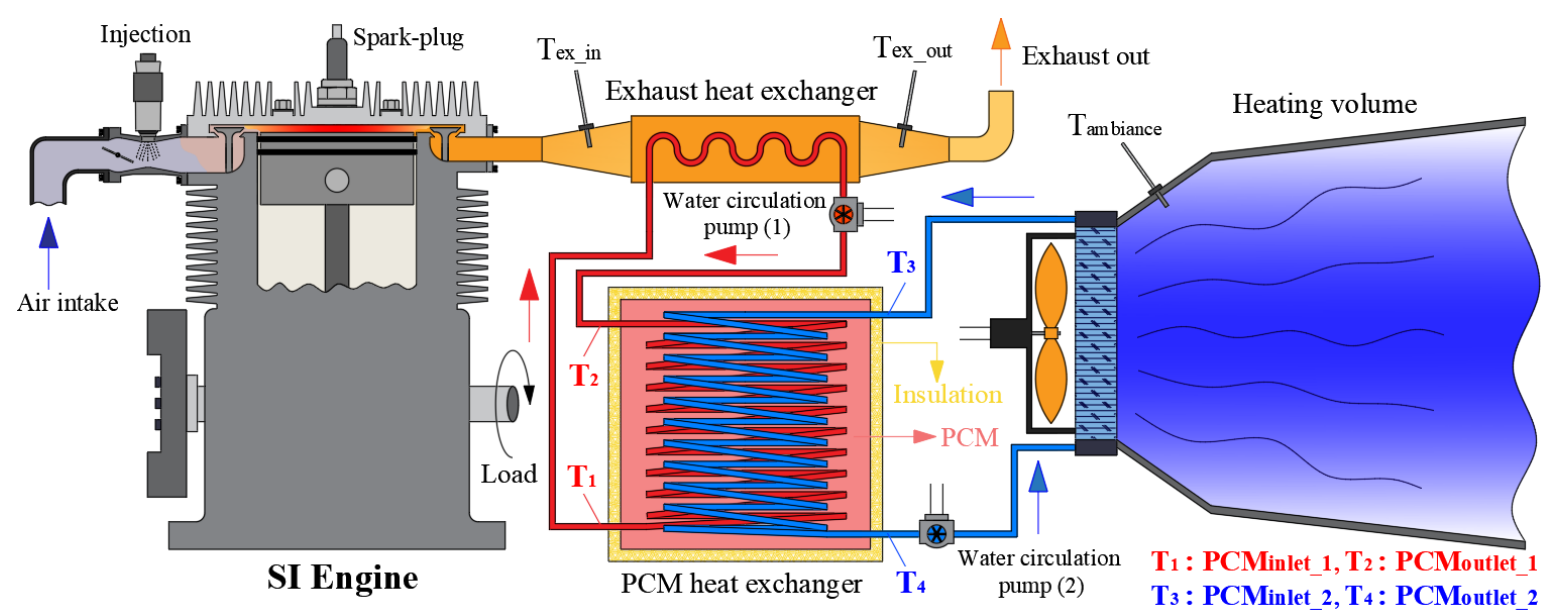

Fig.1. Modelling of LHTES system

Two closed-loop fluid circulation system consisting of two HEXs was planned for charge and discharge of heat to the PCM. A U-tube copper HEX is positioned inside the rectangular prism muffler mounted to the exhaust line of the SI engine for waste heat recovery. In the insulated container where the PCM is stored, two intertwined serpentine tube heat exchangers (STHEX) are designed to be used in the processes of heat discharge and heat charge of PCM. A closed-loop fluid circulation system was consisted between of the outer serpentine tube and the Utube copper HEXs to store some exhaust waste heat in the PCM. To transfer the heat stored in the PCM to the environment to be heated, a second closed-loop fluid circulation system was created between the inner 
serpentine tube and a cooling radiator. It is planned to use water as a heat carrier in the closed-loop fluid circulation systems, and it's to be circulated between the HESs with electric pumps. A cylindrical container with a diameter of $230 \mathrm{~mm}$, a height of $210 \mathrm{~mm}$ and a total internal volume of $8395 \mathrm{~cm}^{3}$ was designed for the storage of PCM. In the container of PCM, the outer STHEX used for the heat charge is designed from copper pipe having $10 \mathrm{~mm}$ pipe outer diameter, and $150 \mathrm{~mm}$ helix diameter and length. The outer serpentine tube has an 8-helical wrapped vertically on top of each other. The STHEX used for the heat discharge is designed having $9 \mathrm{~mm}$ pipe outer diameter, helix 75 helix diameter, and $150 \mathrm{~mm}$ helix length. The inner serpentine tube has a 16-helical wrapped vertically on top of each other. The exhaust muffler has a 190x160x56 mm rectangular prism structure having 62.5 mm length nozzle and diffuser at inlet and outlet and connected to the exhaust line with the help of cylindrical pipes by $43 \mathrm{~mm}$ inner diameter. A U-shaped copper pipe having $7 \mathrm{~mm}$ inner and $9 \mathrm{~mm}$ outer diameter is positioned along the exhaust gas flow to transfer the waste heat from the hot exhaust gases to the water. In numerical analysis,

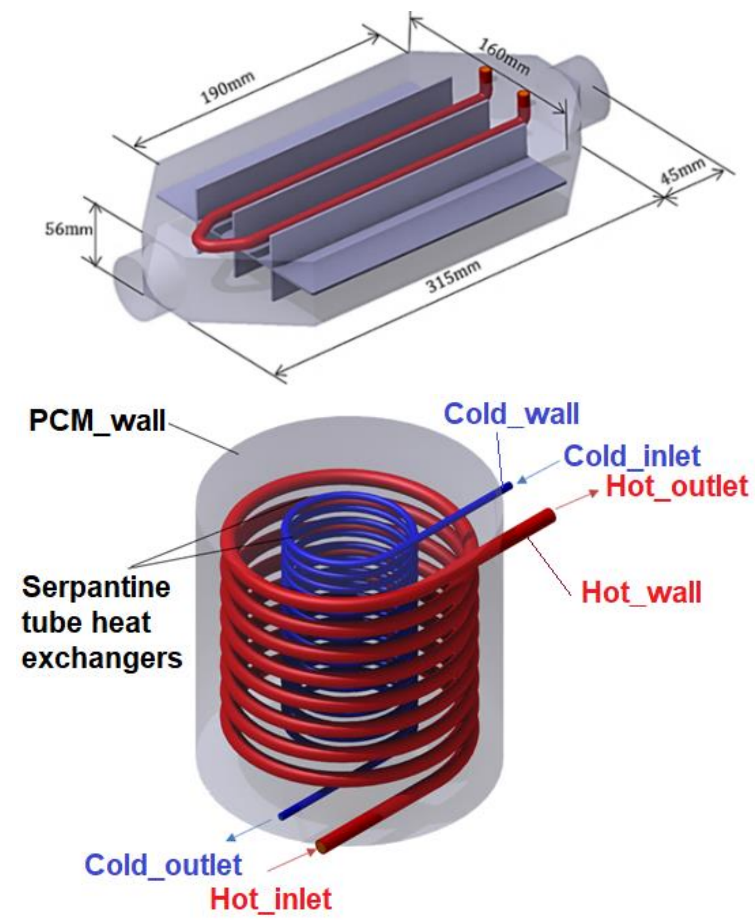

the inlet/outlet of water to the PCM container for the heat charge period and heat discharge period was defined as Hot_inlet/Hot_outlet and Cold_inlet/Cold_outlet, respectively. Also, surfaces of STHEXs were defined as Hot_wall and Cold_wall, respectively. A User-DefineFunctions (UDF) code was developed to calculate the water temperature cyclically in the closed-circuit liquid circulation system. In this code, it calculates the first-time step with the initial limit values and records the surface area average of the temperature values on the surfaces of "Water_outlet", "PCM_outlet (hot or cold)" at the end of the first-time step. At the beginning of the next time step, it moves the values taken from the "Water_outlet" surface to the "PCM_inlet (hot or cold" surface and the values taken from the "PCM_outlet (hot or cold)" surface to the "Water_inlet" surface. This cyclic calculation continues step by step until the numerical analysis completed for both heat charge and heat discharge. Design, boundary conditions and mesh generation steps of the exhaust HEX and PCM container designed for numerical modelling is given in Fig. 2.

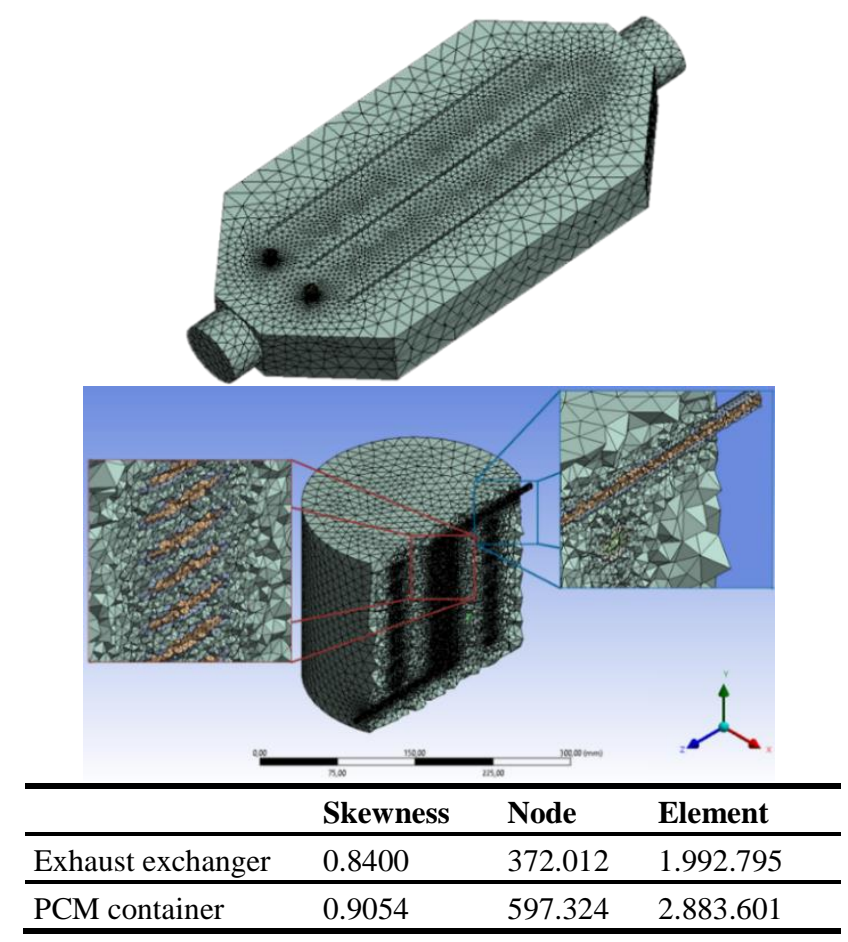

Fig.2. Design, boundary conditions and mesh generation steps of the exhaust HEX and PCM container designed for numerical modelling

\subsection{Governing equations}

The numerical simulations were carried out using the three-dimensional time-dependent turbulent flow model. The presented governing equations were solved timedependent using the ANSYS-Fluent 14.5 software. Also, "User Manual" of ANSYS-Fluent 14.5 software is used in
Eq.1-12 and their explanations [26]. In time-dependent problem solving, number of film sub-time steps was used to advance the film time to the same physical flow time, and the film sub-time step is calculated by "Transient equation" specified in Eq.1. 
$\Delta t=\frac{\Delta t_{\text {flow }}}{N_{\text {film }}}$

Where, $\Delta t_{\text {flow }}$ is the flow time steps, and $N_{\text {film }}$ is the number of film time steps. The general "Continuity equation" reflecting mass conservation for flows incompressible as well as the compressible flow is expressed as in Eq.2.

$\frac{\partial \rho}{\partial t}+\nabla \cdot(\rho \vec{v})=S_{m}$

Where $S_{m}$ is the mass added from one phase to the other in the case of the 2nd different phase, $\rho$ is the density, and $\vec{v}$ is the velocity vector. "Momentum equation" is defined by Eq.3.

$\frac{\partial}{\partial t}(\rho \vec{v})+\nabla \cdot(\rho \vec{v} \vec{v})=-\nabla p+\nabla(\overline{\bar{\tau}})+\rho \vec{g}+\vec{F}$

Where $p$ is the static pressure, $\rho \vec{g}$ is the gravity body force, $\vec{F}$ outer body forces, and $\overline{\bar{\tau}}$ is the stress tensor. $\overline{\bar{\tau}}$ is defined by Eq. 4 .

$\overline{\bar{\tau}}=\mu\left[\left(\nabla \vec{v}+\nabla \vec{v}^{T}\right)-\frac{2}{3} \nabla \cdot \vec{v} I\right]$

Where $\mu$ is the molecular viscosity, $I$ is the unit tensor, and the second term $(2 / 3)$ from the right shows the effect of volume expansion. In the solidification and liquefaction analyses, the modified "Momentum equation" defined in Eq.5 used to take into account the declined porosity in the mushy-zone.

$S=\frac{(1-\beta)^{2}}{\left(\beta^{3}+\varepsilon\right)} A_{m u s h}\left(\vec{v}-\overrightarrow{v_{p}}\right)$

Where $\beta$ is the liquid-fraction and $\varepsilon$ is a very small number that avoids division by zero. $\vec{v}$ and $\overrightarrow{v_{p}}$ are solids velocities (shrinkage velocity) that vary due to the withdrawal of solidified material out of the area. $A_{\text {mush }}$ is the mushy area constant and is defined as $10^{-6}$. The energy equation is defined by Eq. 6 .

$\frac{\partial}{\partial t}(\rho E)+\nabla \cdot(\vec{v}(\rho E+p))=\nabla \cdot\left(k_{e f f} \nabla T-\sum_{j} h_{j} \vec{J}_{j}+\right.$

$\left.\left(\overline{\bar{\tau}}_{e f f} \cdot \vec{v}\right)\right)+S_{h}$

Where $E$ is the total energy, $k_{\text {eff }}$ is the effective heat conduction coefficient, $\vec{J}_{j}$ is the diffusion flux of the $j$ type and $h_{j}$ is the enthalpy of the $j$ type. $S_{h}$ is the heat generated by chemical reaction and/or another heat source identified. The total heat content of the material or enthalpy $(H)$ of the material is calculated as the total $(H=h+\Delta H)$ of sensible heat $(\Delta H)$ and latent heat $(h) . h$ is defined by Eq.7. $h=h_{\text {ref }}+\int_{T_{\text {ref }}}^{T} c_{p} d T$

Where $h_{r e f}$ is the reference enthalpy, $T_{r e f}$ is the reference temperature, and $c_{p}$ is the specific heat at constant pressure. When solidification $\left(T_{\text {solidus }}\right)$ and liquefaction $\left(T_{\text {liquidus }}\right)$ for Eq.7 are defined as the liquid-fraction determined depending on the temperature (Eq.8);

If $\beta=0$ then $T<T_{\text {solidus }}$,

If $\beta=1$ then $T<T_{\text {liquidus }}$

If $\beta=\frac{T-T_{\text {solidus }}}{T_{\text {liquidus }}-T_{\text {solidus }}}$ then $T_{\text {solidus }}<T<T_{\text {liquidus }}$

Where $\beta$ is the liquid-fraction, $T_{\text {solidus }}$ is solidification temperature, and $T_{\text {liquidus }}$ is the liquefaction temperature. The latent heat content $(\Delta H)$ can be formulated by $\Delta H=$ $\beta L$ according to the latent heat value of material in an $\mathrm{L}$ type. $\Delta H$ can be taken a value between zero (for solid) and $L$ (for liquid). Thus, the Eq.9 as a modified form of Eq.6 for PCM analyses in which phase change occurs was obtained.

$\frac{\partial}{\partial t}(\rho H)+\nabla \cdot(\rho \vec{v} H)=\nabla \cdot(k \nabla T)+S$

Where $k$ is the heat transfer coefficient. The sedimentations formed by the change in liquid -fraction during liquefaction and solidification was added to the turbulence equation (Eq.5) to calculate the turbulence in the solidified material and the mushy region, as given in Eq. 10.

$S=\frac{(1-\beta)^{2}}{\left(\beta^{3}+\varepsilon\right)} A_{m u s h} \emptyset$

Where $S$ is the source term describing the decrease in the velocity of the material, $\varnothing$ is the amount of turbulence dissolved $(k, \varepsilon, \omega)$.

The $R N G k-\varepsilon$ model using at the numerical analysis is derived using statistical techniques called renormalization group theory. Transport equations for $R N G k-\varepsilon$ model in the general form are the following (Eq.11 and 12):

$\frac{\partial}{\partial t}(\rho k)+\frac{\partial}{\partial x_{i}}\left(\rho k u_{i}\right)=\frac{\partial}{\partial x_{j}}\left(\alpha_{k} \mu_{\mathrm{e} f f} \frac{\partial k}{\partial x_{j}}\right)+G_{k}+G_{b}-$

$\rho \varepsilon-Y_{M}+S_{k}$

$\frac{\partial}{\partial t}(\rho \varepsilon)+\frac{\partial}{\partial x_{i}}\left(\rho \varepsilon u_{i}\right)=\frac{\partial}{\partial x_{j}}\left(\alpha_{\varepsilon} \mu_{\mathrm{e} f f} \frac{\partial \varepsilon}{\partial x_{j}}\right)+C_{1 \varepsilon} \frac{\varepsilon}{k_{e}}\left(G_{k}+\right.$

$\left.C_{3 \varepsilon} G_{b}\right)-C_{2 \varepsilon} \rho \frac{\varepsilon^{2}}{k_{e}}-R_{\varepsilon}+S_{\varepsilon}$

Where $G_{k}$ is the production of turbulence kinetic energy due to the average velocity gradients defined in the turbulence generation model of the $k-\varepsilon$ module. $G_{b}$ is the generation of turbulence kinetic energy due to the effect of 
Buoyancy in the $k-\varepsilon$ module. $Y_{M}$ is the contribution of unstable expanding compressible turbulence to the total dispersion rate. $\alpha_{k}$ and $\alpha_{\varepsilon}$ are inversely effective Prandtl numbers for $k_{e}$ and $\varepsilon$, respectively. $S_{k}$ and $S_{\varepsilon}$ are userdefined resources. $k_{e}$ is the kinetic energy per mass, $\varepsilon$ is the turbulence dispersion ratio, $\mu_{\text {eff }}$ is the effective dynamic viscosity, $u$ is the velocity vector, $R_{\varepsilon}$ is the gas constant. $C_{1 \varepsilon}$ and $C_{2 \varepsilon}$ are model constants and they get the values of 1.44 and 1.68 , respectively. In the LHTES system as PCM, the paraffin wax commercially identified with code RT27 was used. Thermophysical properties in the solid and liquid-phases of PCM is given in Table 1.

Table 1. Thermophysical properties in the solid and liquid-phases of RT27 [27-29]

\begin{tabular}{c|c|c}
\hline Thermophysical property & Solid-phase & Liquid-phase \\
\hline Density $\left(\mathrm{kg} / \mathrm{m}^{3}\right)$ & 870 & 760 \\
\hline Dynamic viscosity $(\mathrm{Pa} . \mathrm{s})$ & - & 0.02 \\
\hline Specific heat $\left(\mathrm{c}_{\mathrm{p}}\right)-(\mathrm{kJ} / \mathrm{kgK})$ & $3.25(\leq 288 \mathrm{~K})$ & $2.23(\geq 313 \mathrm{~K})$ \\
\hline Thermal conductivity $(\mathrm{W} / \mathrm{mK})$ & 0.24 & 0.15 \\
\hline Latent heat capacity $(\mathrm{J} / \mathrm{kg})$ & \multicolumn{2}{|c}{179000} \\
\hline Thermal expansion coefficient $(1 / \mathrm{K})$ & \multicolumn{2}{|c}{29005} \\
\hline Solidus temperature $(\mathrm{K})$ & \multicolumn{2}{|c}{299} \\
\hline Liquidus temperature $(\mathrm{K})$ & \multicolumn{2}{|c}{} \\
\hline
\end{tabular}

In numerical analysis, the exhaust gas temperature and the mass flow rate were used of gasoline SI engine which is operated under engine speed of $1600 \mathrm{rpm}$, stoichiometric air-fuel mixture, and $1 / 2$ throttle position. SI engine a single-cylinder, air-cooled engine having a stroke volume of $476.5 \mathrm{~cm}^{3}$, maximum output power of $13 \mathrm{HP}$ and torque of $25 \mathrm{Nm}$. To transfer the waste heat from the hot exhaust gases to the PCM container, cold water was used as the heat carrier fluid. Thermophysical properties of exhaust gas and water is given in Table 2. Also, in the analysis of heat charge and discharge periods, the initial boundary conditions accepted for exhaust gas, PCM and water is given in Table 3.

Table 2. Thermophysical properties of exhaust gas and water [30]

\begin{tabular}{c|c|c|c|c|c}
\hline & \multicolumn{4}{|c|}{ Exhaust gas } & Water \\
\hline Temperature $(\mathrm{K})$ & 400 & 600 & 800 & 1000 & 300 \\
\hline$\rho(\mathrm{kg} / \mathrm{m} 3)$ & 0.871 & 0.58 & 0.435 & 0.348 & 998.2 \\
\hline $\mathrm{cp}(\mathrm{kJ} / \mathrm{kgK})$ & 1.014 & 1.051 & 1.099 & 1.141 & 4.182 \\
\hline $\mathrm{k}(\mathrm{W} / \mathrm{mK})$ & 0.0336 & 0.0466 & 0.0577 & 0.0681 & 0.6 \\
\hline$\mu(\mathrm{kg} / \mathrm{ms})$ & 0.0000320 & 0.0000306 & 0.0000370 & 0.0000424 & 0.001003 \\
\hline
\end{tabular}

Table 3. Initially boundary conditions for exhaust gas, water and RT27

\begin{tabular}{c|c|c|c|c}
\hline \multirow{4}{*}{ PCM HEX } & & Hot_wall $(\mathrm{K})$ & Cold_wall $(\mathrm{K})$ & RT27 temperature (K) \\
\cline { 2 - 5 } & Heat charge & 363.15 & - & 293.15 \\
\cline { 2 - 5 } & Heat discharge & - & 273.15 & 363.15 \\
\hline \multirow{4}{*}{ Exhaust HEX } & \multirow{2}{*}{ Water_inlet } & Temperature (K) & \multicolumn{2}{|c}{ Mass flow rate (kg/s) } \\
\cline { 2 - 5 } & \multirow{2}{*}{$\begin{array}{c}\text { Exhaust } \\
\text { gas_inlet }\end{array}$} & 283.15 & \multicolumn{2}{|c}{0.008} \\
\cline { 2 - 5 } & & Temperature (K) & \multicolumn{2}{|c}{ Mass flow rate (kg/s) } \\
\cline { 2 - 5 } & \multicolumn{2}{c}{500} & \multicolumn{2}{c}{0.004} \\
\hline
\end{tabular}

\section{Results and discussions}

The main objectives of this paper are analyzed the timedependent change of heat flow, mean temperature, and liquid-fraction of RT27 in defined boundary conditions. Therefore, time-dependent 3D numerical analyses of processes of heat charge and discharge were performed for designed cylindrical PCM container. However, 2D contour images taken from the vertical middle section of the PCM container at specified time intervals were presented to deal with in detail the temperature and liquid-fraction during the heat charge and discharge processes. In numerical analysis, the example 3D analysis results at $250 . \mathrm{sec}$ and 1000 .sec during the heat charge and discharge processes of RT27 paraffin wax is given in Fig. 3. 


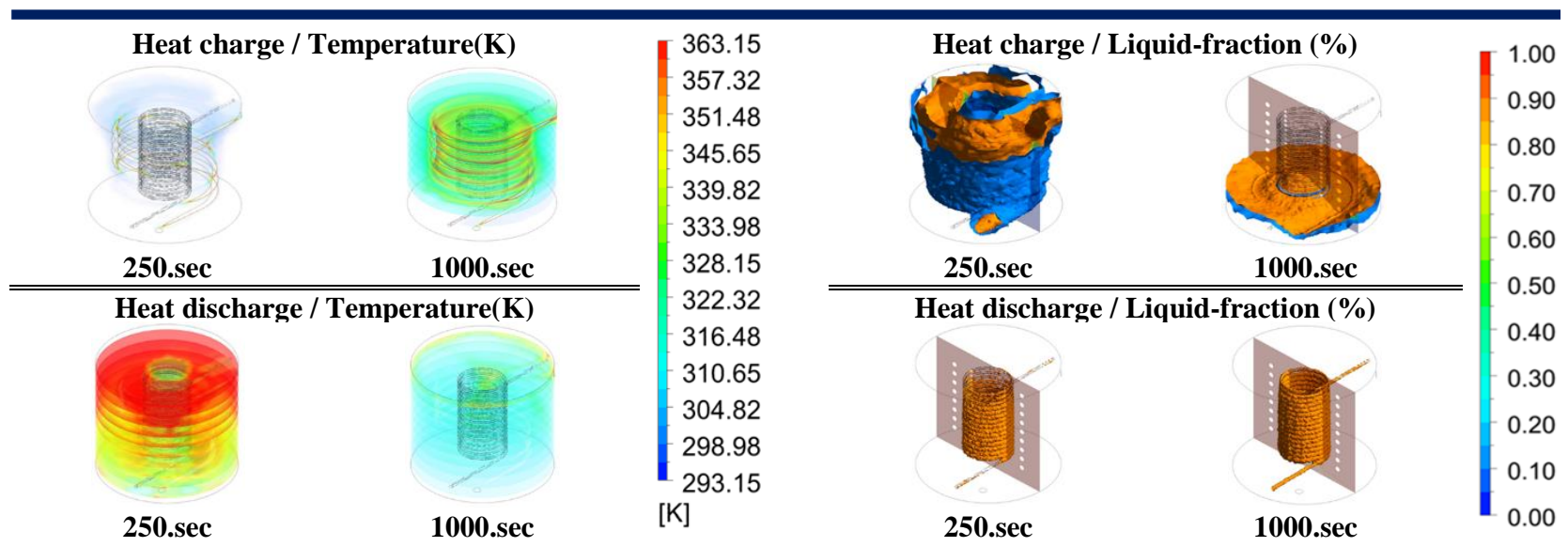

Fig.3. 3D analysis results of the 250.sec and 1000.sec during the heat charge and discharge processes of RT27

Fig. 4 shows the time-dependent variation of heat flux in processes of heat charge and discharge (solidification) of RT27. As shown in Fig. 4, in the heat charge proses RT27 arrived at maximum heat flux in $300 . \mathrm{sec}$ and then decreased rapidly until the approximately 1000 .sec. The first stages of the melting process are conductiondominant heat transfer mode. At this stage, since the narrowness of the liquid nano-PCM layers allows the dominance of the viscous force over the buoyancy, an almost immobile liquid nano-PCM structure prevails [13].
Therefore, the heat flux has a higher value at the beginning of the melting process for RT27. At approximately $3000 . \mathrm{sec}$, the heat flux for RT27 declined at a very low value and remained almost constant until the end of the analysis. At the beginning of the heat discharge process, the heat flux increased rapidly due to the high-temperature difference between the hot STHEX wall and the colder RT27. The heat flow then rapidly decreased until the 6000 .sec and remained almost constant from the 15000.sec to the end of the analysis.

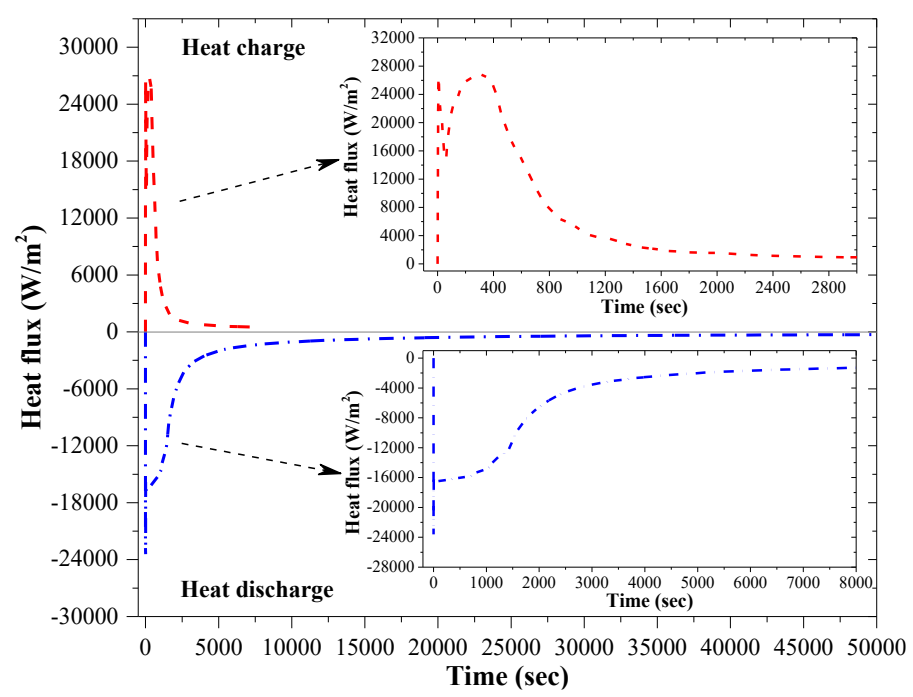

Fig.4. Time-dependent variation of mean heat flux in processes of heat charge and discharge of PCM samples

Time-dependent variation of mean temperature in processes of heat charge is given in Fig. 5. The mean temperature in the PCM container filled with RT27 arrived approximately $316 \mathrm{~K}$ from the initial value of $293 \mathrm{~K}$ at $1000 \mathrm{sec}$. In the early stages of the heat charge process, the increasing heat flux with the conduction-dominant heat transfer mode increased rate of heat transfer from hot water passing through STHEX to the colder RT27 in the PCM container causing rise faster of the mean temperature. After 1000.sec, the slower increased mean temperature of RT27 reached $336 \mathrm{~K}$ at the 8000 .sec. Since the RT27 is in the form of mush in the regions close to STHEX after $1000 . \mathrm{sec}$, the heat flux decreasing with the dominance of natural convection reduced the heat transfer rate, and this caused the temperature increase rate to decrease. With the increase in the percentage of RT27 in mush form in the 
PCM container, the heat transfer rate and temperature increase rate decreased further.

As seen in Fig. 6, initially the temperature gradients have distributed horizontally from the first rings of STHEX to the center of PCM container, then vertically down from the center. After $450 . \mathrm{sec}$, the temperature gradients condensed to a higher value around STHEX and in later stages, the temperatures around STHEX increased to higher values than initially.

As seen in Fig. 5, at the beginning of the melting process (in the range of 0-900 sec), due to the high-temperature difference between the hot STHEX wall and the colder RT27, the rate of melting and hence the increase in the liquid-fraction is higher. The liquid-fraction of RT27 in the PCM container is reached approximately $80 \%$ within the first $900 \mathrm{sec}$. After this time, the increase in the liquidfraction has progressed very slowly, reaching only a maximum of $93 \%$ in 8000 .sec.
The liquid-fraction increased rapidly in the range of 0 $900 \mathrm{sec}$ as can be seen in Fig. 7. Initially, the melting that starts around STHEX and the increase in liquid-fraction spread around the SHTEX to the inner and edge regions of the PCM container. While the rate of increase of the liquidfraction slows down significantly in the range of 900-2000 $\mathrm{sec}$, the liquid-fraction remained almost unchanging between the 2000-8000 sec. 8000 .sec, it appears that there is still some RT27 in the bottom of the PCM container that does not change to the liquid phase. This amount of solid and/or mushy PCM at the bottom of the PCM container is around $7 \%$ as seen in Fig. 5. The amount residue solid and/or mushy PCM was already around $20 \%$ at 900 sec and about $10 \%$ at $2500 . \mathrm{sec}$. As can be seen, the heat transferred to the PCM container after about 2500.sec did not greatly contribute to the completely melting and passing to the liquid phase of RT27.

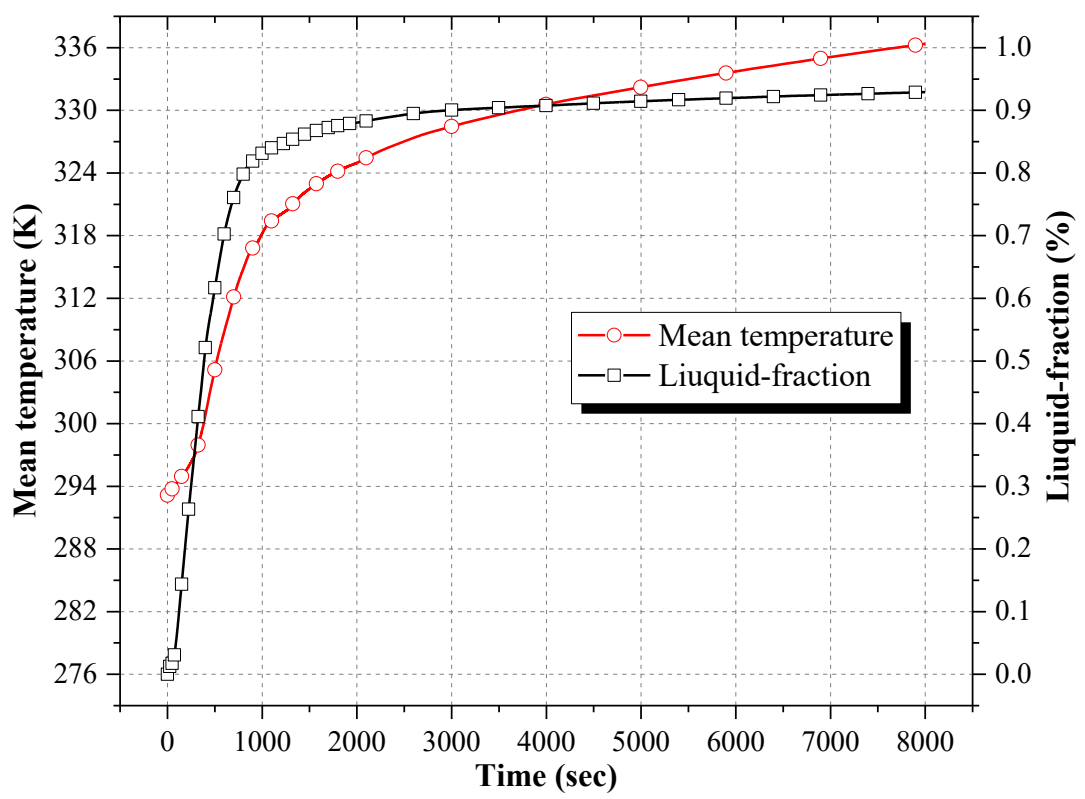

Fig.5. Time-dependent variation of mean temperature and liquid-fraction in process of heat charge 


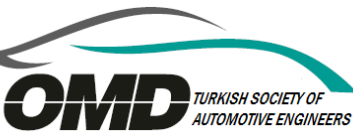

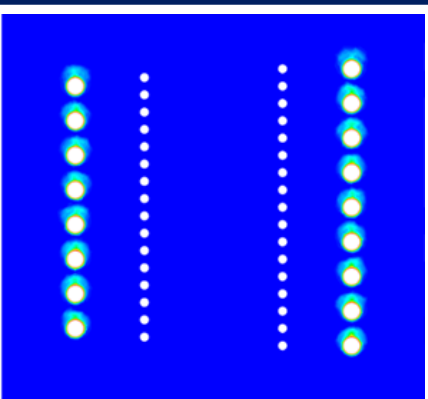

100.sec

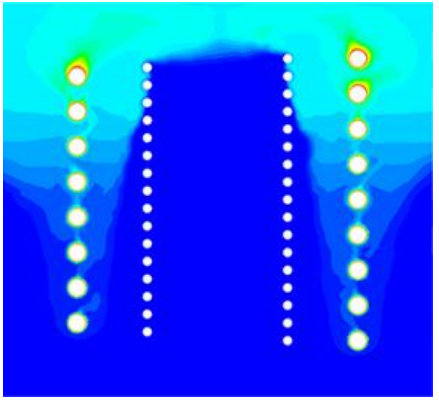

450.sec

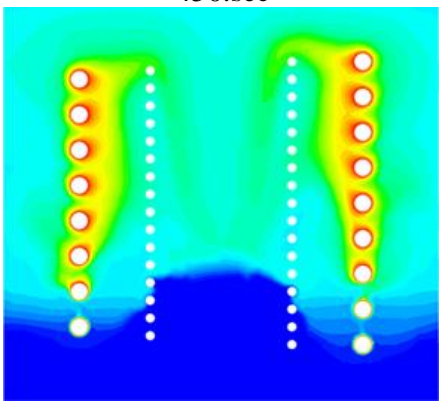

900.sec

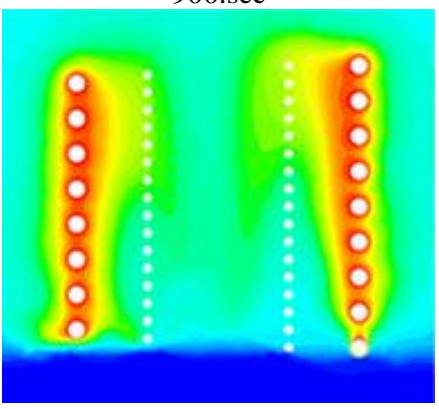

2000.sec

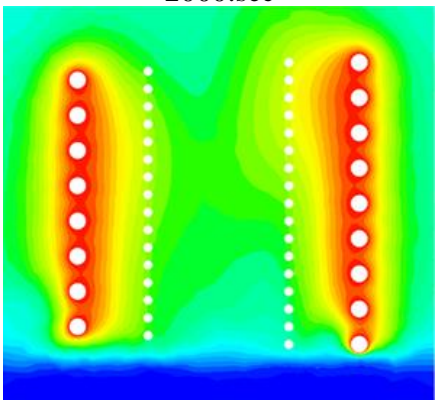

5000.sec

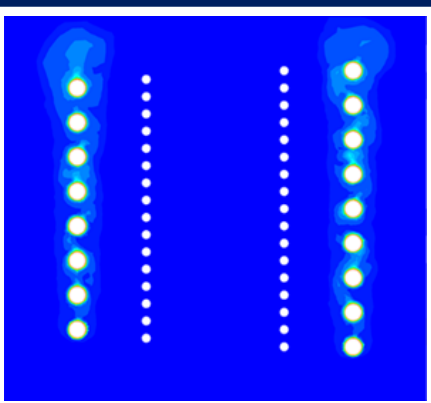

200.sec

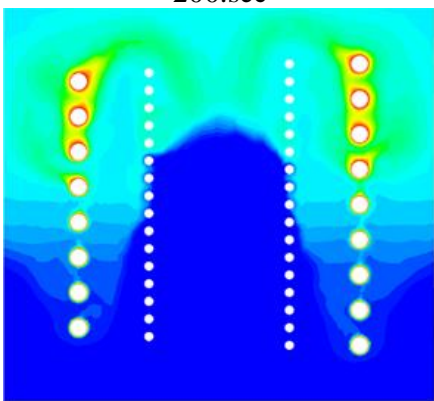

600.sec

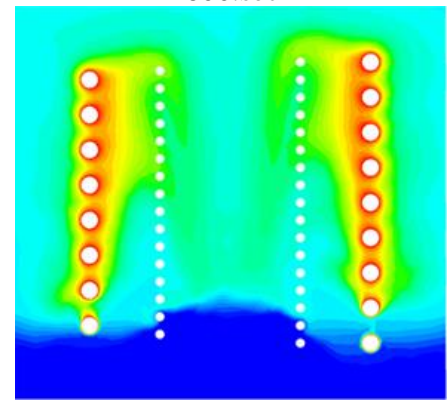

1200.sec

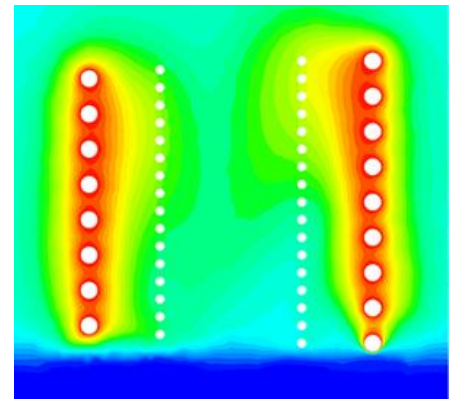

3000.sec

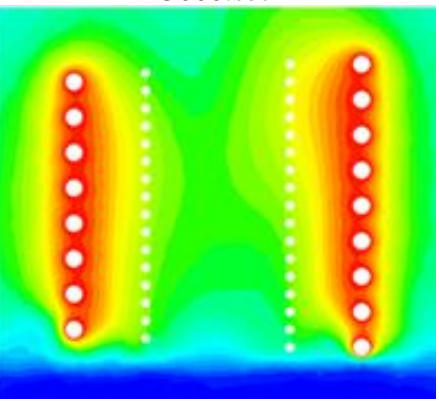

6000.sec

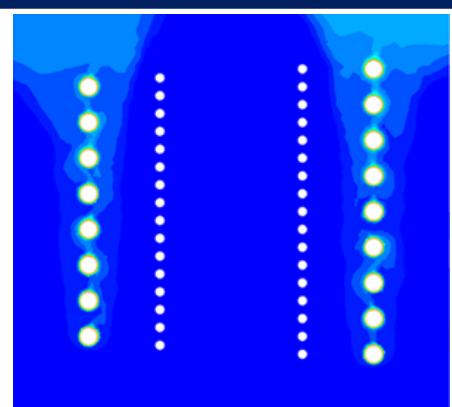

300.sec

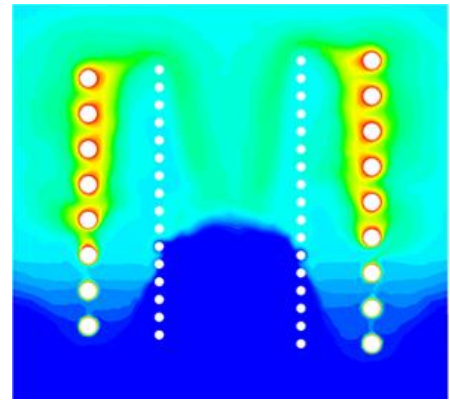

750.sec

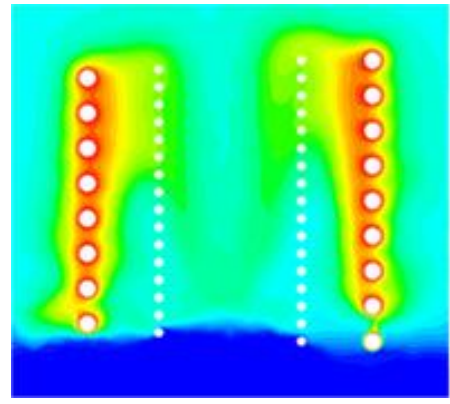

1500.sec

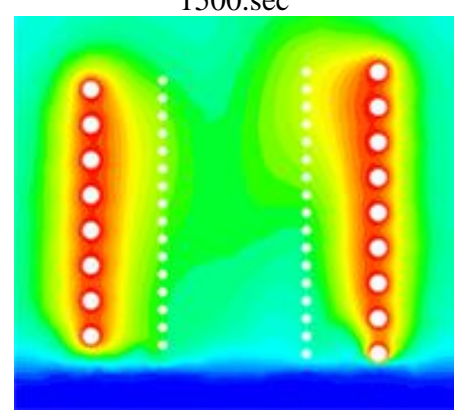

4000.sec

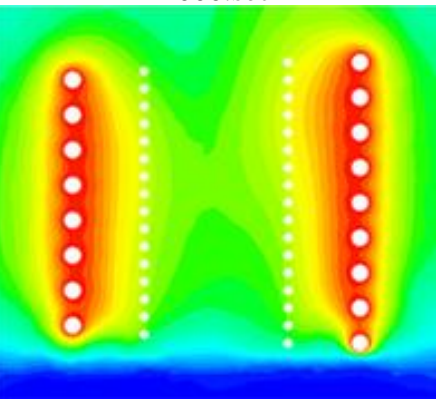

8000.sec
363.15

357.32

351.48

345.65

339.82

333.98

328.15

322.32

316.48

310.65

304.82

298.98

293.15

[K]

Fig.6. Time-dependent variation of temperature contours in process of heat charge 


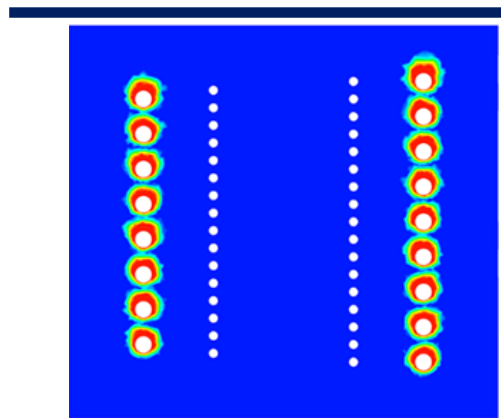

100.sec

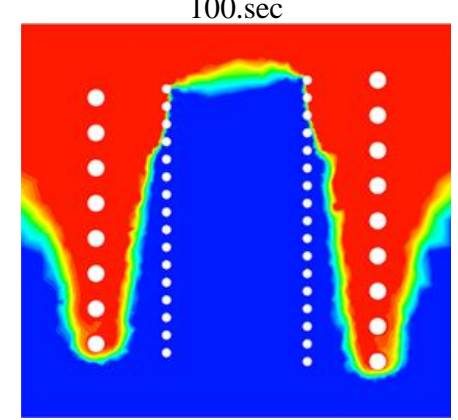

450.sec

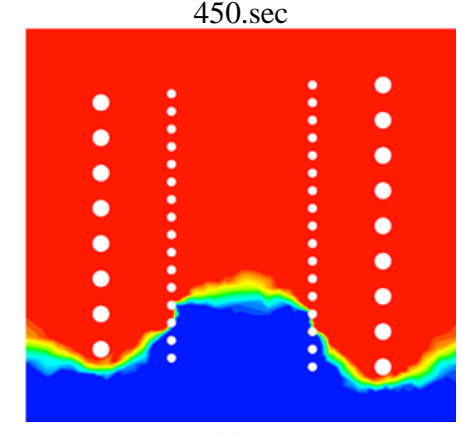

900.sec

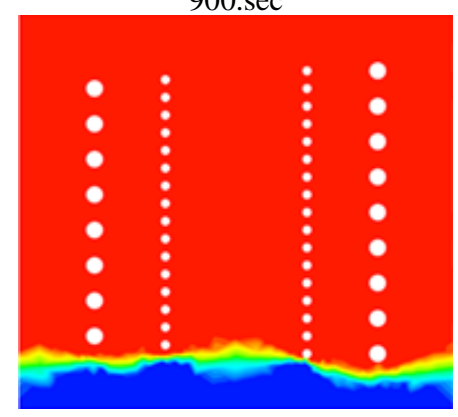

2000.sec

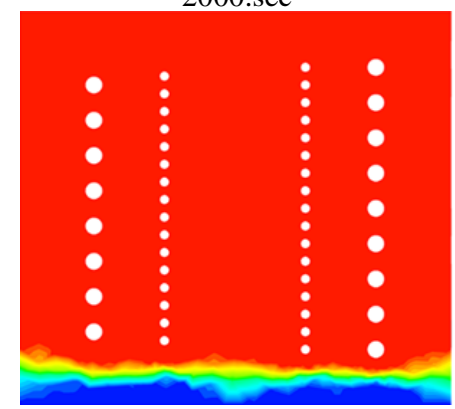

5000.sec

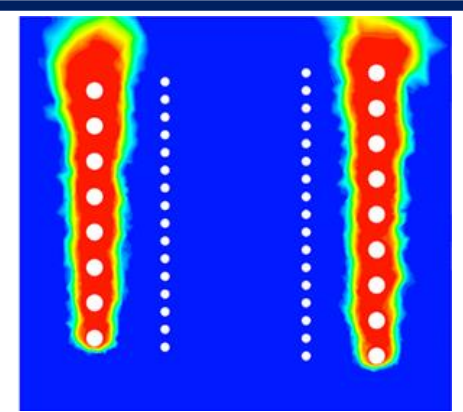

200.sec

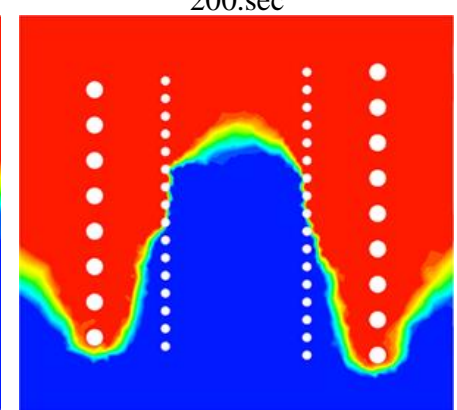

600.sec

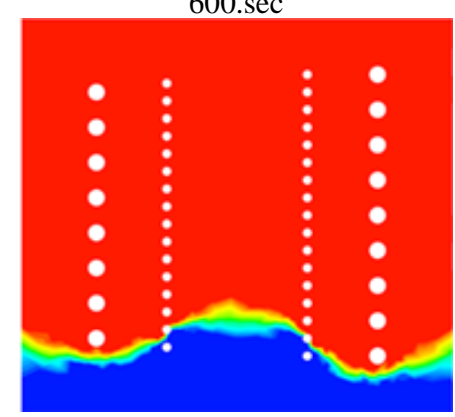

1200.sec

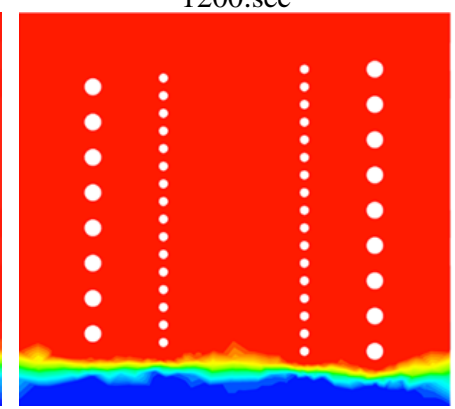

3000.sec

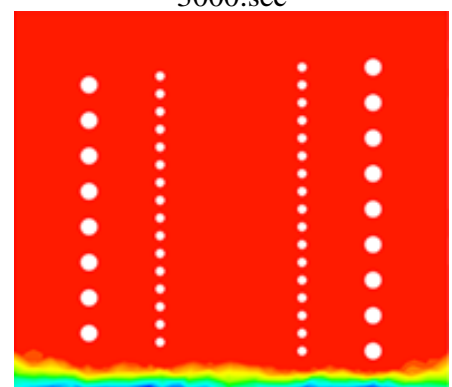

6000.sec

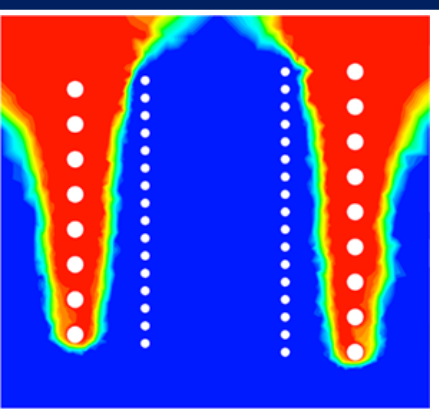

300.sec

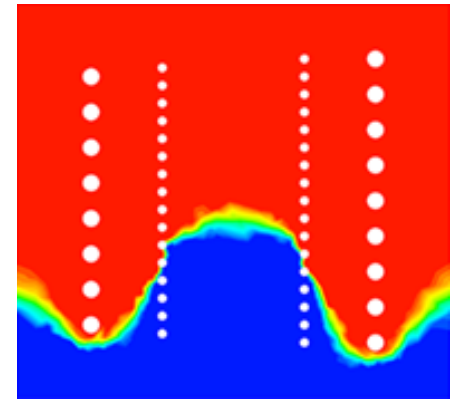

750.sec

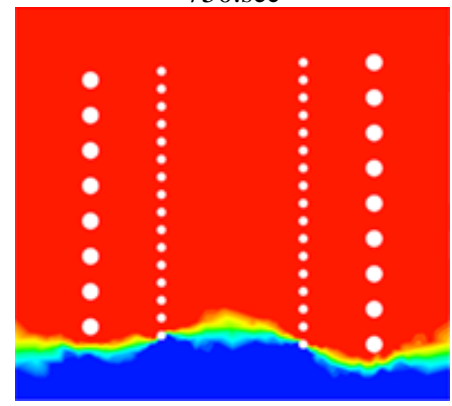

1500.sec

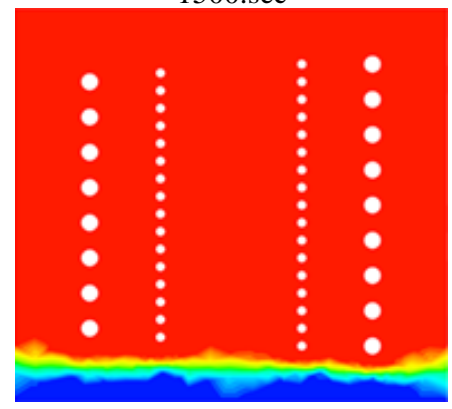

4000.sec

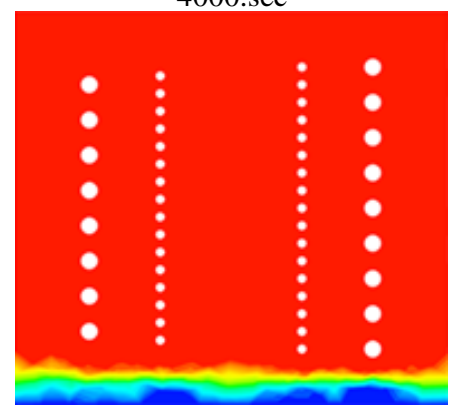

8000.sec

Fig.7. Time-dependent variation of liquid-fraction contours of in process of heat charge 
Time-dependent variation of mean temperature in process of heat discharge is given in Fig. 8. The mean temperature in the PCM container filled with RT27 decreased at approximately $316 \mathrm{~K}$ from the initial value of $363 \mathrm{~K}$ at approximately $900 . \mathrm{sec}$. At the start of the solidification process (in the range of 0-900 sec), due to the high heat flux due to the high-temperature difference between the cold STHEX wall and the warmer RT27, the average temperature of RT27 in the PCM vessel decreased rapidly. After this period, the rate of decrease in the average temperature slowed down significantly and only could be reached $294 \mathrm{~K}$ at the 55000 sec. While the mean temperature decreases from $316 \mathrm{~K}$ to $307 \mathrm{~K}$ in the range of $900-6000 \mathrm{sec}$, decreases linearly from $307 \mathrm{~K}$ to $294 \mathrm{~K}$ in the range of 6000-55000 sec.

As seen in Fig. 9, initially the temperature gradients have distributed horizontally from the inlet rings of STHEX to the center and sides of the PCM container, then vertically to the upper regions of the PCM container. The distribution of temperature gradients was initially very high speed, as in Fig. 8, but slowed down after 900.sec.
As can be seen in Fig. 8, a period in which the liquidfraction almost does not decrease until about $900 \mathrm{sec}$ at the beginning of the heat discharge (solidification) process occurred. In this period, solidification occurred only in a very small area region in around of STHEX. Because the mean temperature approximate $316 \mathrm{~K}$ in the PCM container was much higher than the RT27's solidification temperature of $297 \mathrm{~K}$. The decrease in the liquid-fraction (solidification), the started effectively after about 1000 .sec was reached about $60 \%$ until 6000 .sec. At the end of the $55000 . \mathrm{sec}$, the liquid-fraction of RT27 in the PCM container was declined a low value as $15 \%$, and completed of the solidification process.

As seen in Fig.10, the significant decrease in the liquidfraction started at $1000 . \mathrm{sec}$, and the areas indicated in the color scale, first orange, then green, and finally blue, indicating solidification from red to blue in the PCM container, increased. On the other hand, the solidification started from the lower part of the PCM as the input of cold water of STHEX and proceeded upwards. Also, not fully solidified some RT 27 remained in the upper part and the near regions to the edges of the PCM container.

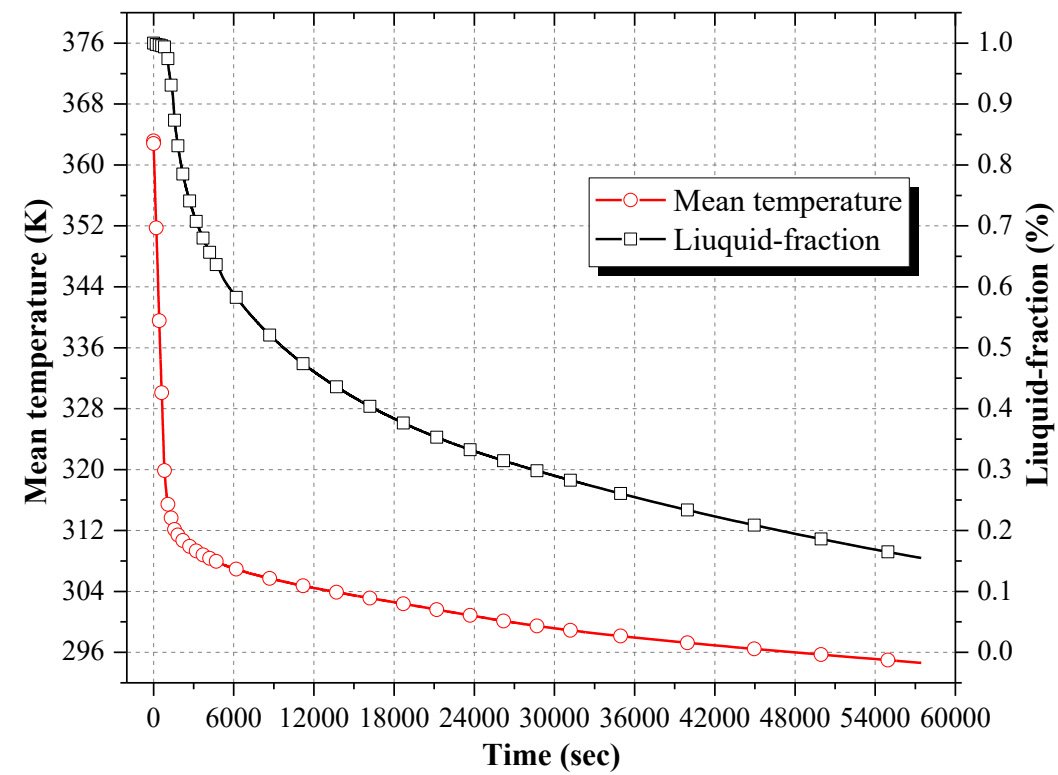

Fig.8. Time-dependent variation of mean temperature and liquid-fraction in process of heat discharge 


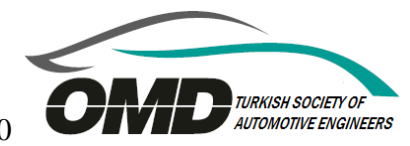

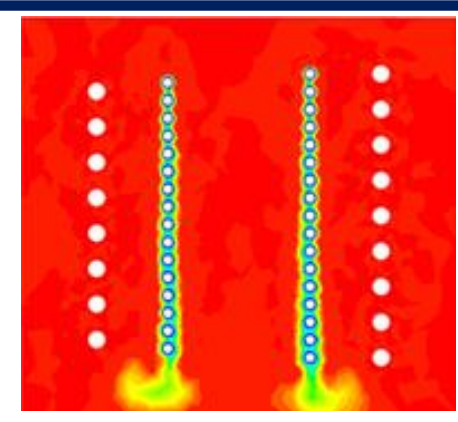

25.sec

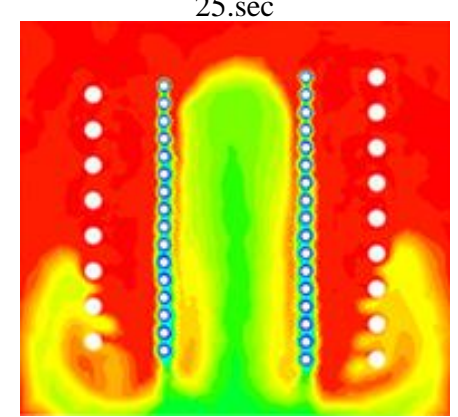

100.sec

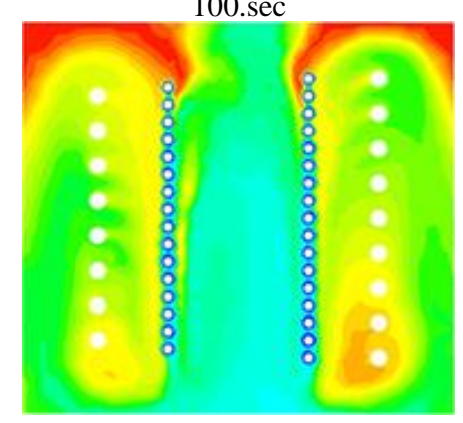

400.sec

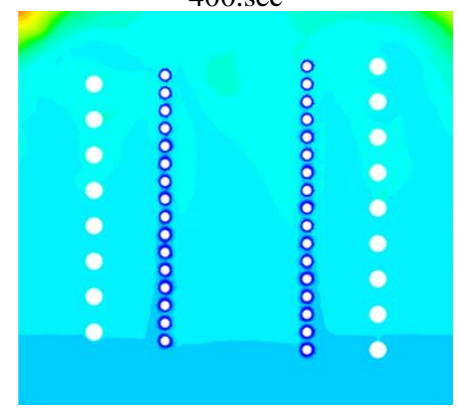

1200.sec

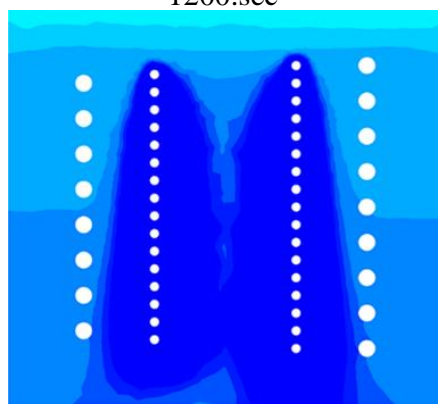

20000.sec

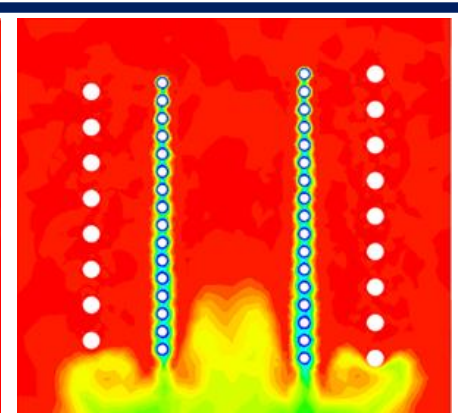

50.sec

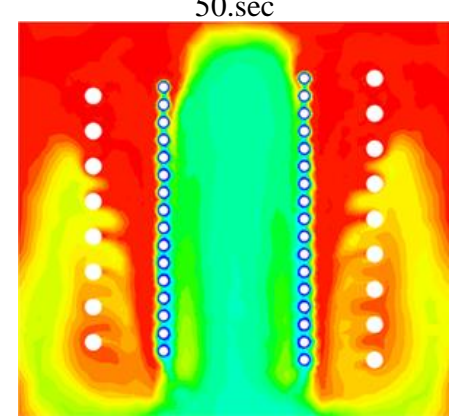

200.sec

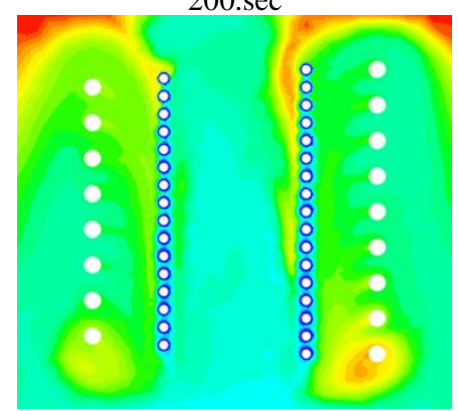

600.sec

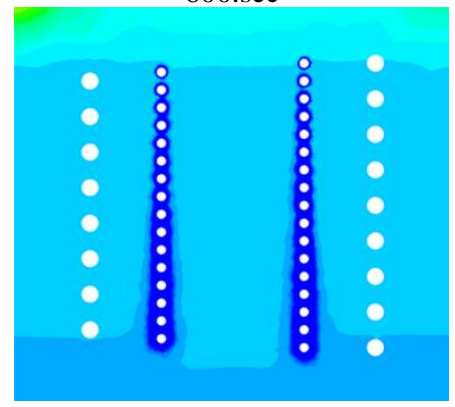

2500.sec

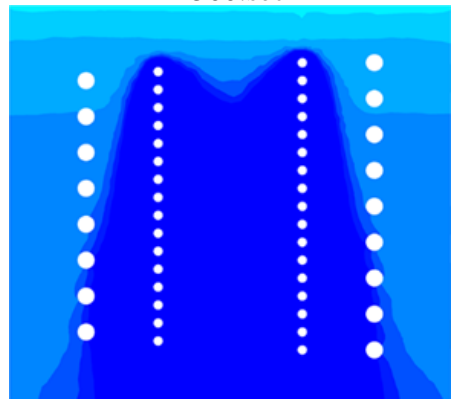

$30000 . \mathrm{sec}$

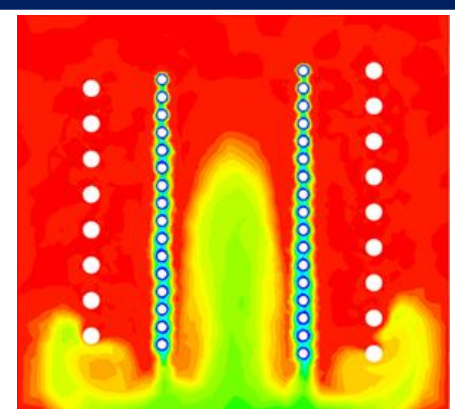

75.sec

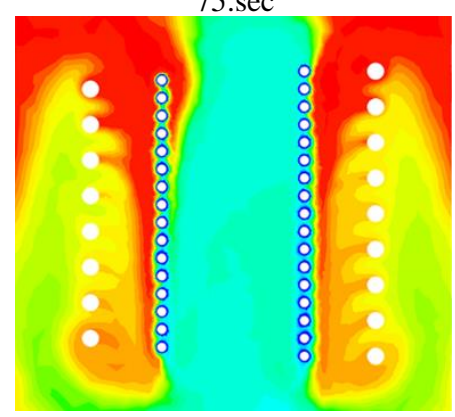

300.sec

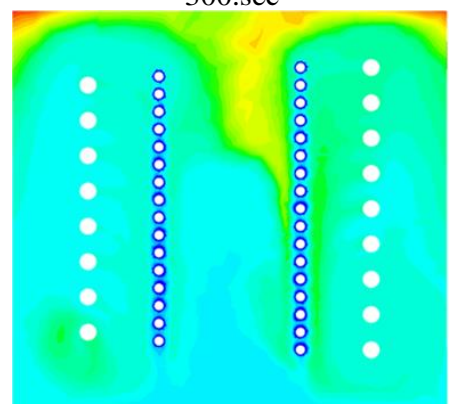

800.sec

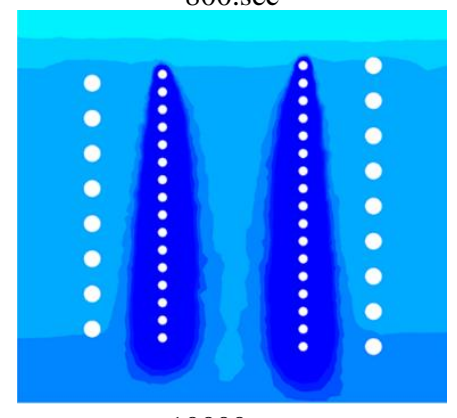

10000.sec

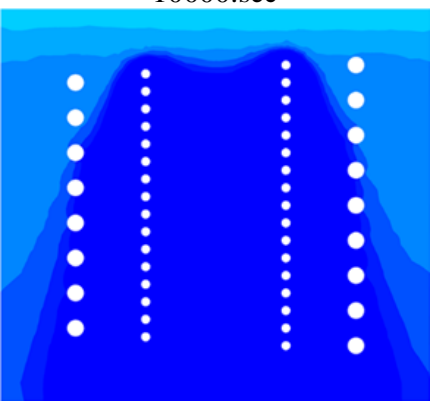

55000.sec
363.15

357.32

351.48

345.65

339.82

333.98

328.15

322.32

316.48

310.65

304.82

298.98

293.15

[K]

Fig.9. Time-dependent variation of temperature contours in process of heat discharge 


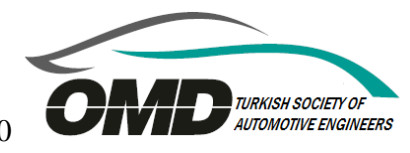

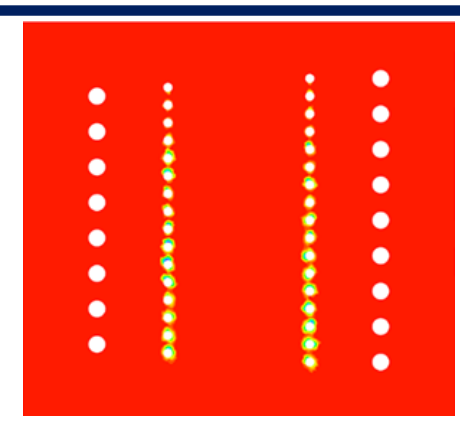

200.sec

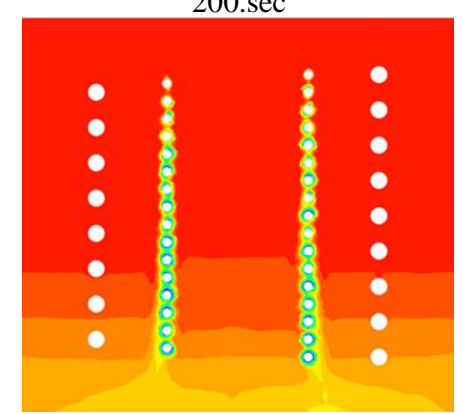

1200.sec

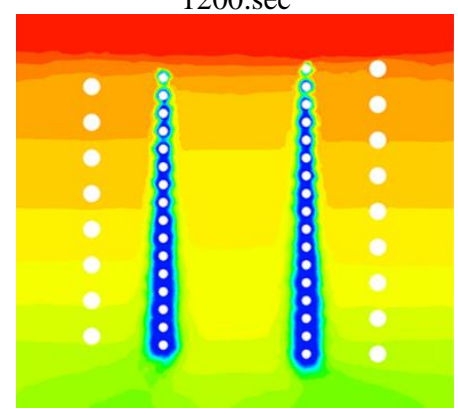

2500.sec

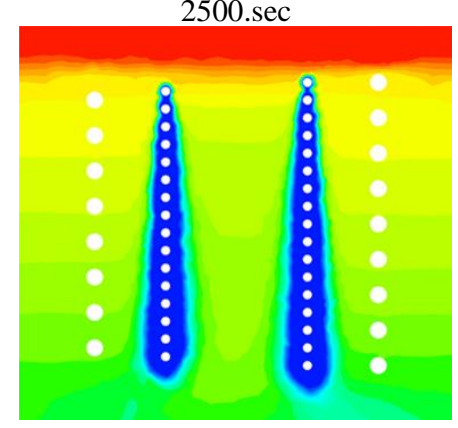

5000.sec

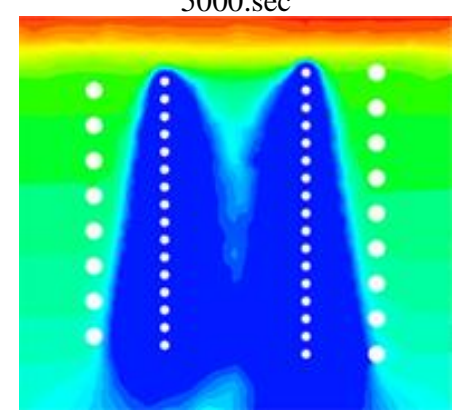

20000.sec

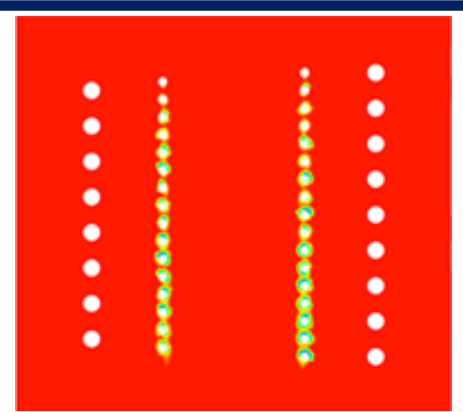

600.sec

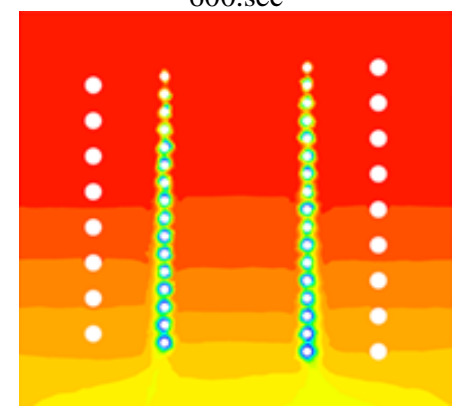

1400.sec

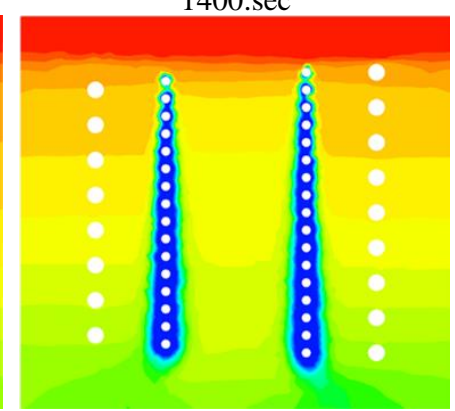

3000.sec

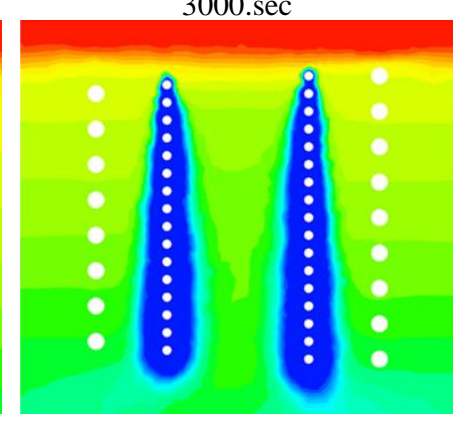

7000.sec

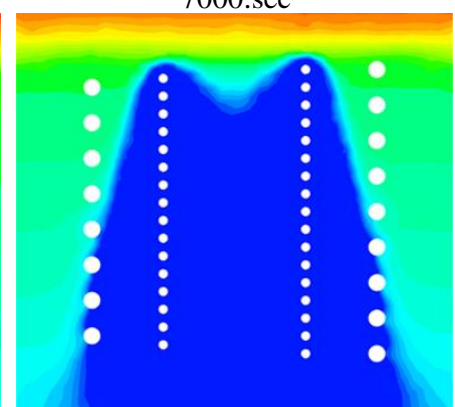

$30000 . \mathrm{sec}$

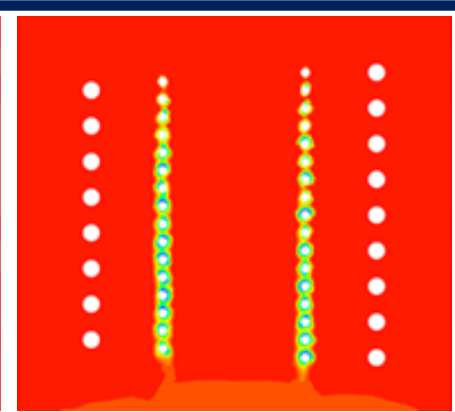

1000.sec

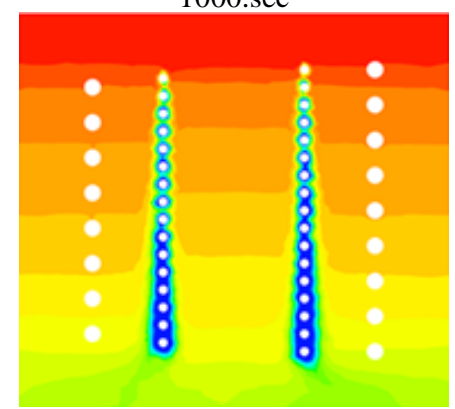

2000.sec

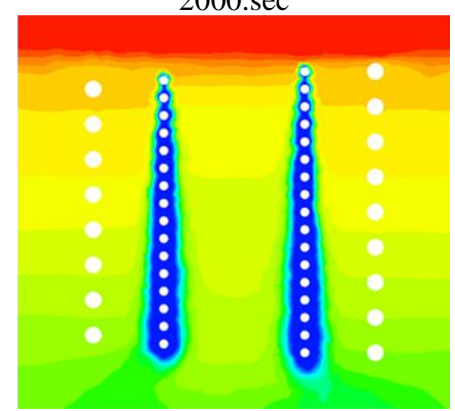

3500.sec

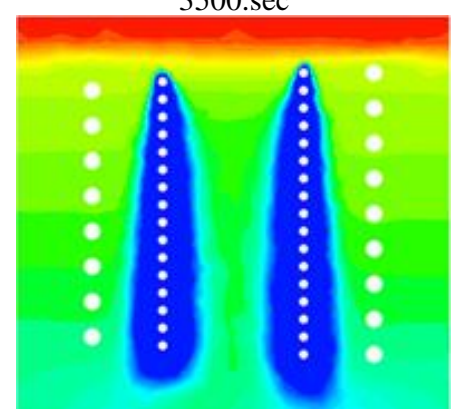

10000.sec

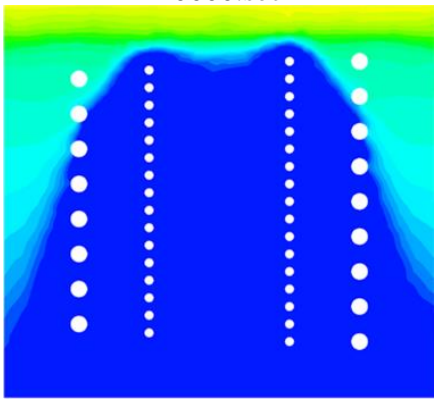

55000.sec

Fig.10. Time-dependent variation of liquid-fraction contours in process of heat discharge 


\section{Conclusions}

The findings obtained in the numerical analyses of heat charge (melting) and discharge (solidification) processes using RT27 paraffin wax in the LHTES system designed for the exhaust waste heat recovery of a typical SI engine are summarized following;

- In the RT27's heat charge process, the maximum heat flux at $300 . s e c$ was reached, and then the heat flux decreased rapidly up to $1000 . \mathrm{sec}$. At this stage, conduction heat transfer is dominated. After 3000.sec the heat flux declined to a very low value and remained almost constant until the end of the analysis. In the RT27's heat discharge process, in the beginning, the heat flux increased rapidly due to the high-temperature difference between the hot STHEX wall. Then, heat flux decreased rapidly until the 6000.sec and remained almost constant from the 15000 .sec to the end of the analysis.

- At the beginning of the heat charge process, the heat flux hence heat transfer rate rapidly increased due to the conduction dominant heat transfer mode, so the mean temperature of RT27 and the liquid-fraction rapidly increased, too. In the later stages, due to the predominance of natural convection, the heat flux hence heat transfer rate decreased, so the increasing trend of both the mean temperature and of the liquidfraction of RT27 slowed down. Also, although increased slightly of the mean temperature after $3000 . \mathrm{sec}$, the liquid-fraction has remained almost constant. At the end of the analysis (at 8000.sec) the mean temperature of RT27 in the PCM container reached $336 \mathrm{~K}$ and the liquid-fraction to $93 \%$. The analysis was terminated as the increase in temperature and liquid-fraction came to a near stop.

- At the start of the heat discharge (solidification) process due to the high heat flux due to the hightemperature difference between the cold STHEX wall and the warmer RT27, the mean temperature of RT27 in the PCM vessel decreased rapidly. However, the solidification could not begin up to $1000 . \mathrm{sec}$, as the temperature could not rise to the solidification temperature $(297 \mathrm{~K})$ of RT27. At the end of the analysis (at 55000.sec) the mean temperature of RT27 in the PCM container declined $294 \mathrm{~K}$ and the liquidfraction to $15 \%$.

- As a result, the process of heat charge completed at 8000 .sec with $93 \%$ liquid-fraction, while the process of heat discharge completed in a very long time such as $55000 . \mathrm{sec}$ with $15 \%$ liquid-fraction.

\section{Acknowledgements}

This study is performed as part of an M.Sc. thesis entitled, 'CFD Analysis of Storage and Re-use by PCM of Exhaust Waste Heat Energy in an Internal Combustion Engine (in Turkish)'. The M.Sc. thesis was written by Durukan ATEŞ [31] under the supervision of Associate Professor Habib Gürbüz.

\section{References}

[1] Farid, M.M., Khudhair, A.M., Razack, S.A.K. and Hallaj, S.A. (2004). A review on phase Change energy storage: materials and applications. Energy Conversion and Management. 45, 1597-1615.

[2] Hatami, M., Ganji, D.D. and Gorji-Bandpy M. (2014). A review of different heat exchangers designs for increasing the diesel exhaust waste heat recovery. Renewable Sustainable Energy Reviews. 37, 168-181.

[3] Hasanuzzaman, M. Rahim, N.A., Saidur, R. and Kazi, S.N. (2011). Energy savings and emissions reductions for rewinding and replacement of industrial motor, Energy. 36(1), 233-240.

[4] Gürbüz, H. and Demirtürk S. (2020). Investigation of dualfuel combustion by different port injection fuels (neat ethanol and E85) in a DE95 diesel/ethanol blend fuelled CI engine. Journal of Energy Resources Technology. 142(12):122306.

[5] Gürbüz, H., Demirtürk, S., Akçay, İ.H. and Akçay, H. (2020). Effect of port injection of ethanol on engine performance, exhaust emissions and environmental factors in a dual-fuel diesel engine, Energy and Environment, https://doi.org/10.1177/0958305X20960701.

[6] Gürbüz, H., Şöhret, Y. and Akçay, H., (2019). Environmental and Enviroeconomic Assessment of an LPG Fueled SI Engine at Partial Load. Journal of Environmental Management. 241, 631-636.

[7] Balakrishna, B. and Mamidala, S. (2014). Design optimization of catalytic converter to reduce particulate matter and achieve limited back pressure in diesel engine by CFD. International Journal of Current Engineering and Technology. 2, 651-658.

[8] Patil, A.A., Navale, L.G. and Patil, V.S. (2013). Simulative analysis of single cylinder four stroke C.I. engine exhaust system. International Journal of Science, Spirituality, Business and Technology. 2(1), 79-82.

[9] Hatami, M., Boot, M.D., Ganji, D.D. and Gorji-Bandpy M. (2015). Comparative study of different exhaust heat exchangers effect on the performance and exergy analysis of a diesel engine, Applied Thermal Engineering. 90, 23-37.

[10]Hatami, M., Ganji, D.D. and Gorji-Bandpy M., (2015). Experimental and numerical analysis of the optimized finned-tube heat exchanger for OM314 diesel exhaust exergy recovery. Energy Conversion and Management. 97, 26-41. 
[11]Barba, A. and Spiga, M. (2013). Discharge mode for encapsulated PCMs in storage tanks, Solar Energy. 74, 141148.

[12]Dhaidan, N.S. (2017). Nanostructures assisted melting of phase change materials in various cavities. Applied Thermal Engineering.111,193-212.

[13]Cui, Y., Xie, J., Liu, J., Wang, J. and Chen, S. (2017). A review on phase change material application in building. Advanced in Mechanical Engineering. 9(6), 1-15.

[14]Ebadi, S., Tasnim, S.H., Aliabadi, A.A. and Mahmud, S. (2018). Melting of nano-PCM inside a cylindrical thermal energy storage system: Numerical study with experimental verification, Energy Conversion and Management. 166, 241259.

[15]Zalba, B., Marin, J.M., Cabeza, L.F. and Mehling, H. (2003). Review on thermal energy storage with phase change: Material, heat transfer analysis and applications. Applied Thermal Engineering. 23, 251-283.

[16]Wang, Z., Zhang, Z., Jia, L. and Yang, L. (2015). Paraffin and paraffin/aluminum foam composite phase change material heat storage experimental study based on thermal management of Li-ion battery. Applied Thermal Engineering. 78, 428-436.

[17]Yadav, C. and Sahoo, R.R., (2019). Exergy and energy comparison of organic phase change materials based thermal energy storage system integrated with engine exhaust. Journal of Energy Storage, 24, 1-8.

[18]Tiari, S., Qiu, S. and Mahdavi, M. (2015). Numerical study of finned heat pipe-assisted thermal energy storage system with high temperature phase change material. Energy Conversion and Management. 89, 833-842.

[19]Mehling, H. and Cabeza, L.F. (2008). Heat and Cold Storage with PCM. An Up to Date Introduction into Basics and Applications, Springer, Berlin.

[20]Sharifi, N., Bergman, T.L., Allen, M.J. and Faghri, A. (2014). Melting and solidification enhancement using a combined heat pipe, foil approach. International Journal of Heat and Mass Transfer. 78, 930-941.

[21]Pandiyarajan, V., Pandian, M.C., Malan, E., Velraj, R. and Seeniraj, R.V. (2017). Experimental investigation on heat recovery from diesel engine exhaust using finned shell and tube heat exchanger and thermal storage system. Applied Energy. 88, 77-87.

[22]Hatami, M., Jafaryar, M., Ganji, D.D. and Gorji-Bandpy M. (2014). Optimization of finned-tube heat exchangers for diesel exhaust waste heat recovery using CFD and CCD techniques. International Communications in Heat and Mass Transfer. 57, 254-263.

[23]Dhaidan, N. and Khodadadi, J. (2015). Melting and convection of phase Change materials in different shape containers: A review. Journal of Renewable and Sustainable Energy Reviews. 43, 449-477.

[24]Wang, S., Faghri, A. and Bergman, T.L. (2012). Melting in cylindrical enclosures: numerical modeling and heat transfer correlations, Numerical Heat Transfer Part A: Applications. 61, 837-859.

[25]Shmueli, H., Ziskind, G., and Letan, R., (2010). Melting in a vertical cylindrical tube: numerical investigation and comparison with experiments, International Journal of Heat and Mass Transfer. 53, 4082-4091.

[26]ANSYS FLUENT, 14.5. (2014). User's and theory guide. Canonsburg, Pennsylvania, USA: ANSYS, Inc.

[27]Trigui, A., Karkri, M., Boudaya, C., Candau, Y., Ibos, L. and Fois, M. (2017). Experimental investigation of a composite phase change material: Thermal-energy storage and release. Journal of Composite Materials. 48(1), 49-62.

[28]Shen, J., Neveu P., Shu, S. and Falcoz, Q., (2016). Geometry optimization of a latent heat thermal energy storage unit using RT27. 5th International Conference On Environment, Materials, Chemistry And Power Electronics (EMCPE 2016), April 11-12 Zhengzhou, China.

[29]Durakovic, B. and Torlak, M. (2017), Experimental and numerical study of a PCM window model as a thermal energy storage unit. International Journal of Low-Carbon Technologies. 12, (3), 272-280.

[30]Perry, R.H. (1984). Perry's Chemical Engineers Handbook, McGraw-Hill, New York, 6th edition.

[31]Ateş, D. (2019). CFD Analysis of Storage and Re-use by PCM of Exhaust Waste Heat Energy in an Internal Combustion Engine (in Turkish). Master Thesis, Süleyman Demirel University, Graduate-School of Natural and Applied Sciences, Isparta, Turkey. 